\title{
Effect of educational status on oral health education program amongst Anganwadi workers in improving oral health of preschool children of Muradnagar block, Ghaziabad-A cross-sectional study
}

\author{
Preeti Bhagia $^{1 *}$, Ipseeta Menon ${ }^{2}$, Ricky Pal Singh $^{3}$, Anubhav Sharma ${ }^{4}, J_{y o t i}$ Goyal ${ }^{5}$, Deepa Tomar ${ }^{6}$ \\ ${ }^{1,5}$ PG Student, ${ }^{2}$ Professor, ${ }^{3}$ Reader, ${ }^{4}$ Senior Lecturer, ${ }^{6}$ Private Practitioner ${ }^{1-5}$ Dept. of Public Health Dentistry, I.T.S Centre for \\ Dental Studies \& Research, Ghaziabad, Uttar Pradesh, ${ }^{6}$ Ghaziabad, Uttar Pradesh, India
}

*Corresponding Author:

Email: bhagia.preeti@yahoo.com

\begin{abstract}
Aim: To study effect of educational status of Anganwadi Workers on oral health education program and its impact on improving oral health of preschool children in Muradnagar block, Ghaziabad.

Materials and Methods: Study was done amongst 30 Anganwadi Centres of Muradnagar selected by simple random sampling. Sample size was calculated to be 503. Anganwadi Workers were divided into four groups depending on their educational status. Pre tested questionnaire was used to assess baseline knowledge of Anganwadi workers on oral health. Oral health education was imparted to them. Clinical examination of preschool children attending Anganwadi centres was done at baseline and after oral health education program. Data was analysed using descriptive statistics and Statistical Package for Social Sciences software version 18.

Results: Mean values of knowledge scores were found to be higher in Anganwadi workers (36.7) with high educational status leading to higher improvement $(76 \%)$ in oral health status of preschool children.

Conclusion: Educational Status of Anganwadi Workers has a significant impact on their oral health knowledge and efficiency of improving oral health status of preschool children.
\end{abstract}

Keywords: Educational status, Anganwadi workers, Pre school children.

\section{Introduction}

India is a developing country with $70 \%$ of its population living in villages. ${ }^{1}$ Poor educational status is one of the major reasons for poverty stricken conditions in rural areas of Muradnagar which leads to unaffordable medical facilities in the block. Primary health care services play a major role to provide the most affordable and accessible oral health care services in India. Anganwadi Workers (AWW's) play a significant role by being the central point for the delivery of services at community levels to preschool children, pregnant and lactating women, nursing mothers and adolescent girls. ${ }^{2}$ They form an integral part of Integrated Child Development Scheme and play an active role in growth and development of the child. ${ }^{3}$

Oral health care is not the main priority in India due to which it is extremely important for us to empower primary health care workers and create a model. AWW's have a major role to play in the nutrition and oral health of children. Knowledge, Attitude and Practice (KAP) of AWW's is the most important factor in determining their role and skills in reducing early childhood caries and improving oral health of preschool children. ${ }^{4}$ Oral Health Educational Program for primary health care workers engaging with preschool children can be a change making intervention in the community promoting oral health.

Educational status of AWW's is a key factor in determining their efficiency to disseminate their knowledge to preschool children and their caregivers. Recruitment of AWW's with low educational status is an obstacle in assuring qualitative and appropriate delivery of services to the target population as anganwadi workers with low literacy levels often have low oral health knowledge. ${ }^{5}$

This study was done to study effect of educational status of AWW's on oral health education program and its impact on improving oral health of preschool children in Muradnagar block, Ghaziabad.

\section{Materials and Methods}

A cross sectional survey was conducted on preschool children of Muradnagar to assess the relationship between educational status of AWW's and oral health outcome of preschool children. Ethical clearance from the ethical committee of I.T.S-CDSR Muradnagar and approval from child development project officer to conduct oral health education program amongst Anganwadi workers was obtained before start of the study. Before participation of AWW's and clinical examination of children, written consent from AWW's, Anganwadi centre authorities and parents of children were taken. Oral Health Education Program was designed using the training manual for health workers, National Oral Health Care Program highlighting preschool children's basic oral health and hygiene measures, common dental problems and their treatment modalities. Duration of the study was 3 months and collection of the data was carried out between January- March 2018.

A pilot study was carried out on 50 (10\%) preschool children of 2 Anganwadi centres in the month of December 2017 to check operational feasibility and 
implementation before the main survey through clinical examination and questionnaire followed by necessary modifications. A self administered close ended questionnaire comprising of 30 questions was used to record demographic details and educational status of AWW's and comprised of questions to assess their knowledge on oral health of preschool children. Content validity was assessed by Cronbach's Alpha test whose validity index was 0.9. Calibration of the principal investigator was done in the Department of Public Health Dentistry I.T.S- CDSR Muradnagar, Ghaziabad. To reduce the intra examiner variability, examinations on them were repeated by the investigator.

Assuming 95\% confidence interval, the sample size was calculated by using the formula -

$\mathrm{n}=\mathrm{Z}^{2} \mathrm{P}(1-\mathrm{P}) / \mathrm{d}^{2}$

Where, $\mathrm{P}=$ Expected prevalence rate which was estimated to be $70 \%$ after literature review and pilot study.

$\mathrm{Z}=\mathrm{Z}$ statistic for a level of confidence (For the level of confidence of $95 \%$, which is conventional, $Z$ value is 1.96 ).

$\mathrm{d}=$ Precision (Least permissible error which was taken at $4.0 \%$ ).

Using the above formula, the estimated sample size was 503

\section{Inclusion criteria:}

1. Written informed consent from parents of the children included in the study.

2. 3 to 5 years old children present on the day of examination

3. Fully erupted primary dentition of children

4. AWW's who were registered by the government during the year 2017

\section{Exclusion criteria:}

1. Children with systemic health problems.

2. Children with special needs

3. AWW's who were absent on the scheduled date and time of the fixed training schedule

Data Collection: AWW's of 40 Anganwadi centres were divided equally into 4 categories depending on their educational status: 1. AWW's who completed primary education 2. AWW's who completed high school 3. AWW's who completed intermediate education 4. AWW's who completed graduation or any other higher degree. Depending on the educational status of AWW's, preschool children were also categorized. Baseline data of oral health knowledge of selected AWW's was collected before intervention by the study assessment questionnaire. Knowledge scores were divided into 3 categories: - 1.Good (21-30) 2. Fair (11-20) 3.Poor (0-10). The lowest score could be 0 and highest could be 30 . Similarly oral health status of preschool children was recorded at baseline before intervention by clinical examination using Debris Index- Simplified (DI-S) ${ }^{6}$ and decayed, extracted, filled teeth index (deft). Oral health education program was then conducted in 3 sessions amongst AWW's. Different sessions were conducted in a gap of 3 weeks by a 1 hour health talk. After 1 week of every session, reinforcement of the knowledge was done by similar method of 1 hour health talk. After 1 week of reinforcement, post intervention data of oral health knowledge was collected by the same questionnaire. At the end of the study, post intervention data of oral health status of preschool children was recorded by the clinical examination in a similar way as in baseline. The proformas were coded by an intern and then arranged in stacks together. Labelling of the bundles was done to the make them ready for data entry which was done on the same day to rectify any kind of discrepancy.

\section{Inspection, Scrutiny and clarifications}

To assess any missing information, assessment forms were rechecked.

\section{Statistical Analysis}

It was carried out in 2 steps.

1. Data compilation and presentation

2. Analysis of data statistically

SPSS 18.0 was used for the analysis of the data. Compilation of data was done systematically. After decoding the assessment proformas master table was prepared in Microsoft excel. Presentation and distribution of data was done meaningfully. All Descriptive and Inferential statistics were calculated and represented by Mean \pm SD (Min-Max) and Numbers (\%). P value was taken as not significant (p value: $p>0.05$ ), significant ( $p$ value: $0.01<P<0.05$ ) or, highly significant ( $\mathrm{p}$ value: $\mathrm{p}<0.01)(<\mathrm{P}<0.05)$ or, highly significant ( $\mathrm{p}$ value: $\mathrm{p}<0.01$ ).

\section{Results}

Among 503 preschool children who participated in the study, 59\% were girls and $46 \%$ were boys (Fig1). $9 \%$ of children were in the age group 2 to 3 years old, $51 \%$ in age group 3 to 4 years old and $40 \%$ in age group 4 to 5 years old. Fig. 2

Educational status of AWW's showed significant relation with their oral health knowledge and children's oral health outcome. After Oral Health Educational Program there was an increase in percentage of AWW's with correct responses (Fig. 3) and improvement in oral health knowledge scores of AWW's (Fig. 4). AWW's with higher educational level showed higher improvement in knowledge scores in comparison to AWW's with lower educational level.

Clinical findings of children were directly proportional to AWW's knowledge scores. At the end of the study when clinical examination was done it was seen that there was improvement in DI-S scores (Fig. 5) and deft scores (Fig. 6) of children in comparison to baseline.

Knowledge scores showed direct relation with children's DI-S AND deft scores. AWW's with higher educational level were able to bring more improvement 
in oral health status of the children in comparison to AWW's with lower educational level (Fig. 7).

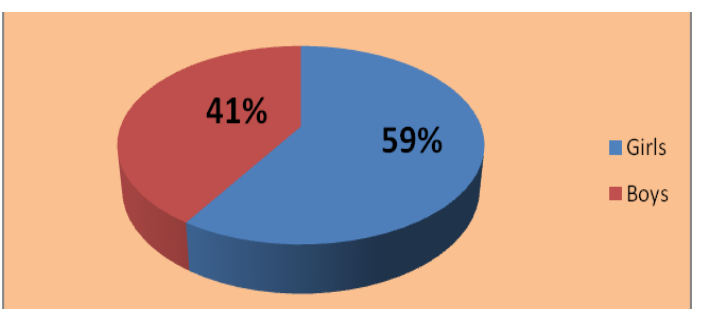

Fig. 1: Distribution of study population on the basis of gender

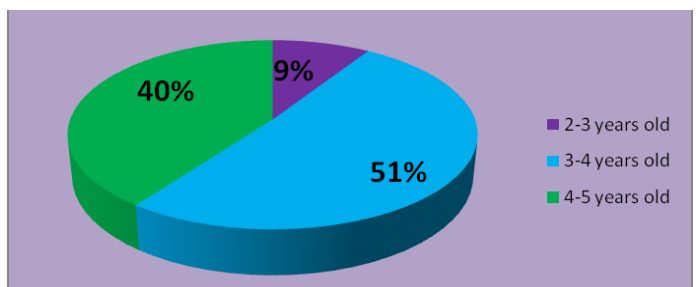

Fig. 2: Distribution of study population on the basis of age group

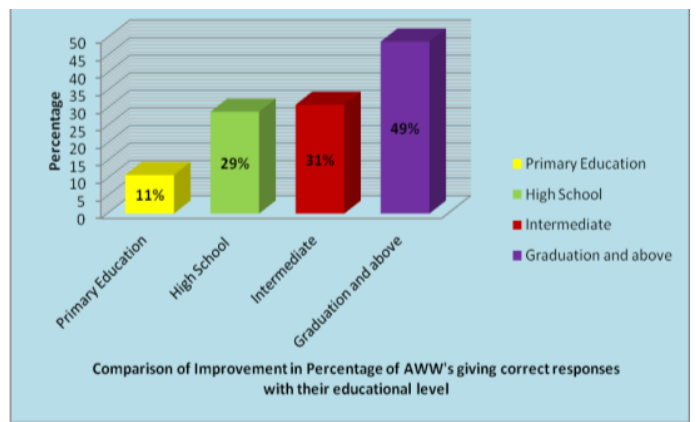

Fig. 3: One way ANOVA test used followed by Boneforroni test for inter group comparison $(F=$ 0.792, $P=0.031$ )

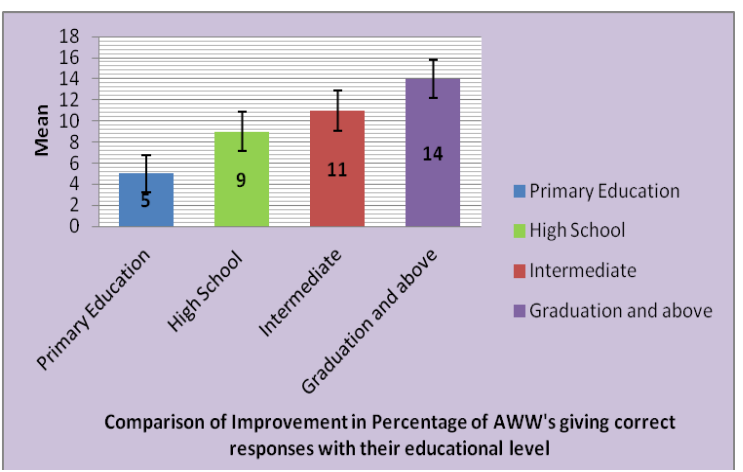

Fig. 4: One way ANOVA test used followed by Boneforroni test for inter group comparison $(F=$ 1.616, $P=0.029$ )

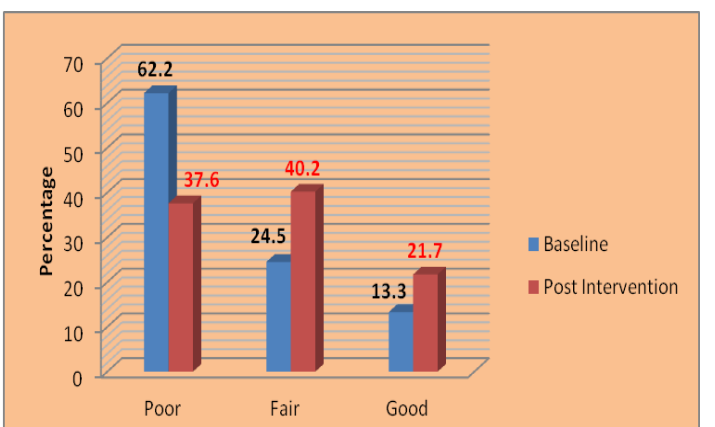

Fig. 5: Comparison of DI-S scores of preschool children at baseline and post intervention

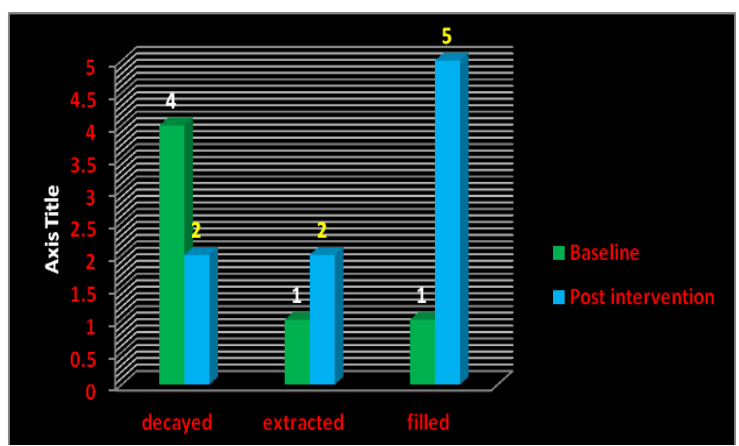

Fig. 6: Comparison of mean decayed, extracted and filled teeth of preschool children at baseline and post intervention

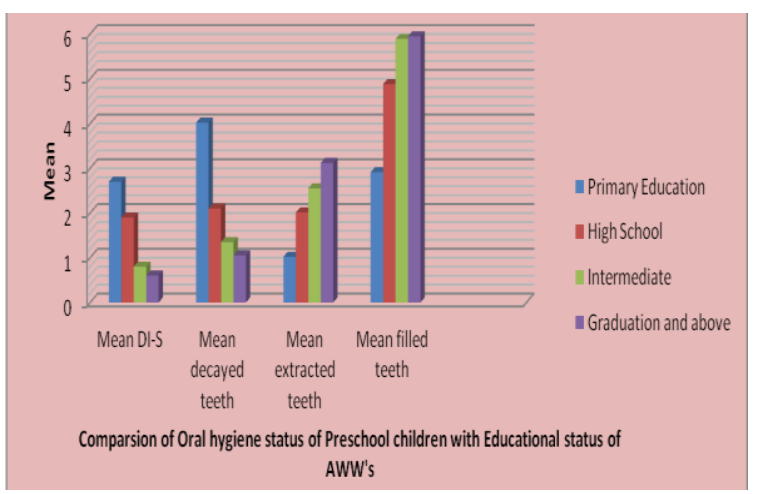

Fig. 7: One way ANOVA test used followed by Boneforroni test for inter group comparison $(F=$ $1.414, p<0.001)$

\section{Discussion}

As per our knowledge, it is one of the foremost study to assess the impact of educational status of AWW's on oral health outcomes of preschool children in Muradnagar.

One of the most commonly occurring dental diseases in preschool children is early childhood caries which may further lead to maloclussion and many other dental problems. ${ }^{7}$ Educational status of Anganwadi workers is one of the obstacles in improving oral hygiene of preschool children as per the results of this study.

The findings of the present study are supported by clinical literature. In our study, it was seen that oral health education program was effective as there was 
improvement in oral health knowledge scores of AWW's post intervention in comparison to baseline which is similar to study conducted by Sandhaya MP et al. ${ }^{8}$

Oral health knowledge scores of AWW's were directly proportional to their educational status which is similar to study conducted by Yogesh et al. ${ }^{4}$ Study highlighted the fact that educational status of the AWW's thereby had an impact on health outcome of preschool children and these findings were similar to studies conducted by Tyagi $\mathrm{U}$ et $\mathrm{al}^{5}$ and Shah A et al. ${ }^{9}$ A study by Raj $\mathrm{S}^{10}$ on AWW's and preschool children also demonstrated similar results.

deft scores are found to be the best predictor for early childhood caries. ${ }^{11}$ It was seen after oral health education program at the end of the study that there was reduction in DI-S scores and deft scores of preschool children of Muradnagar as stated in the studies conducted by Relwani AH et al ${ }^{12}$ and Sandhaya YK et al. ${ }^{13}$ To improve oral hygiene status of preschool children best approach would be to recruit AWW's with higher educational status and use preventive and therapeutic treatment modalities in combination. ${ }^{14}$

There are some limitations in the study. Long term assessment of the improvements need to be evaluated on regular basis by further studies because improvement in oral hygiene of study population may exist only during the programme for a shorter duration of time period. Other factors of AWW's like their age, socioeconomic status and experience were not assessed due to which results cannot be generalized.

Several strengths of the study are also present. It provides the association of all the three factors together:- educational status of AWW's, improvement in oral health knowledge scores of AWW's after oral health education program, their ability to improve oral health status of preschool children and impact of educational status of AWW's on health outcome of children; which is rare to be found in a single study. A calibrated and trained examiner did the clinical examination which was done to evaluate the proper outcome.

Our study has a public health significance also. To improve the knowledge, attitude and practice of AWW's regarding oral health it provides a baseline model for future oral health education interventions. It may refute some government policy implications where it is not mandatory to recruit AWW's of higher educational status.

It also gives opportunity for AWW's to disseminate their knowledge in improving oral health status of preschool children.

Conflict of Interest: None.

\section{References}

1. Bullet in on Rural Health statistics in India. New Delhi: Issued by Infrastructure Division, Dept. Of Family Welfare, Ministry of Health and Family Welfare (MoHFW), Nirman Bhavan; 2003.

2. Kakodkar P, Matsyapal CK, Ratnani N, Agrawal R, Anganwadi workers as Oral Health Guides: An interventional study. J Dent Res Sci Develop 2015;2(2):33-37.

3. Kant 1, Gupta A, Mehta SP. Profile of anganwadi workers and their knowledge about ICDS. Indian J Pediatr 1984;51(4):401-2.

4. Yogesh, Singh A, Mamta, Thriveni BS, Satpathy SK.. Knowledge, attitude and practice of Anganwadi workers about oral health in Palwal district. Int J Adv Res 2015;3(10):1958-1965

5. Tyagi U, Menon I, Tomar D, Singh A, Goyal J. Association between maternal oral health literacy and their preschoolers' oral health outcomes in Muradnagar A cross-sectional study. J Dent Specialities 2017;5(2):98101.

6. Greene JC, Vermillion JR. The simplified oral hygiene index. Jam Dent Assoc 1964; 68:7-13.

7. Biswal I, Nagarajappa R, Srivastava BK. Association between parenting stress and early childhood caries in 4-5 years preschool children of Moradabad. Int J Pub Health Dent 2010;1:1-4.

8. Sandhaya MP, Shanthi M, Fareed N, Sudhir KM, Kumar RVSK. Effectiveness of oral health education among primary health care workers at the primary health centre in Nellore district, Andhra Pradesh. J Indian Assoc Public Health Dent 2014;12(2):74-79

9. Shah AF, Ibrahim I, Jan SM, Baba IA. Impact of Oral hygiene training of anganwadi workers on improvement of oral hygiene in rural child population of Jammu and Kashmir. Int J Med Sci Public Health 2017;6(8):1325-29

10. Raj S, Goel S, Sharma VL, Goel NK. Short term impact of oral hygiene training package to Anganwadi workers on improving oral hygiene of preschool children in North Indian city. 2013;13:67.

11. Menon I, Nagarajappa R, Ramesh G, Tak M. Parental stress as a predictor of early childhood caries amongst preschool children in India. Int J Paediatr Dent 2013;23(3):160-65.

12. Relwani AH, Kiran S, Bhatt R, Patel M. Impact of Dental Health Education on "Specific Learning Needs" Children. Int J Clin Pediatr Dent 2016; 9(1):31-4.

13. Sanadhya YK, Thakkar JP, Divakar DD, Pareek S, Rathore K, Yousuf A, Ganta S, Sobti G, Maniar R, Asawa K, Tak M, Kamate S. Effectiveness of oral health education on knowledge, attitude, practices and oral hygiene status among 12-15-year-old schoolchildren of fishermen of Kutch district, Gujarat, India. Int Marit Health 2014;65(3):99-105.

14. Menon I. Preventive Dentistry-Practice from Womb to Tomb. EC Dental Science 2017;15:01

How to cite the article: Bhagia P, Menon I, Singh RP,
Sharma A, Goyal J, Tomar D. Effect of educational status
on oral health education program amongst Anganwadi
workers in improving oral health of preschool children of
Muradnagar block, Ghaziabad-A cross-sectional study. J
Dent Specialities 2018;6(1):136-139.

